\section{Rules of engagement}

\section{Biologists may soon have little option but to sign up} to codes of conduct.

1 hy don't people resent driving licences? After all, most

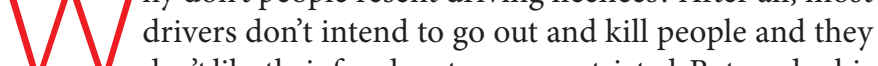
don't like their freedom to roam restricted. But road vehicles can be turned into a means of destruction, whether through carelessness, mischief or malice. People accept, therefore, a licence that reinforces rules designed to help keep people safe.

Substitute 'organisms' for 'road vehicles' and 'researchers' for 'drivers' and you have a case for the licensing of biologists. And however outrageous Nature readers may consider it, politicians and policy-makers are taking codes of conduct and licensing in research seriously. This much was clear from last week's inaugural meeting of the US National Science Advisory Board for Biosecurity (NSABB). Just a US problem? Applicable only to defence labs? Think again. Any biologists whose work could be misused (and they are many) face growing pressure to reassure their fellow citizens. This would also pre-empt excessive regulation by a willingness to declare explicitly just how responsible they intend to be.

Most researchers would wonder what planet such proposals come from. Speaking at the NSABB meeting, a social scientist, Brian Rappert of Exeter University, UK, described discussions with 600 biologists in the United Kingdom, most of whom were blissfully unaware of issues of 'dual use' that learned societies, biological weapons convention negotiators and others have been fretting about for years. Speakers from the intelligence services and weapons inspectorates emphasized, however, the active interest in the harmful uses of biology they have encountered among a malevolent few.

The approach favoured at the NSABB's preliminary discussions

was to all but accept that genies cannot be kept in bottles, and to focus instead on developing a 'culture of responsibility' in research institutions, journals and, especially, among individuals (see Nature 435, 860;2005). Engineers and medics are imbued with a culture that, if ignored, can lead to professional prohibition. For most basic researchers, codes of behaviour, although taken for granted where safety and human or animal experimentation are concerned, are alien when it comes to broader professional practice.

Consider the phrase 'do no harm'. Deceptively simple, a trite piece of motherhood and apple pie, and yet, as one medical researcher at the meeting said, this fundamental principle had provided him with significant help when faced with some critical professional decisions.

\section{"If codes are to carry any weight they will need to be backed by certification, and institutions will have to extend their means of assuring compliance."}

As Rappert highlighted, many codes for biologists have been drafted, ranging from such statements of aspiration to enforceable codes of practice (see www.projects.ex.ac.uk/codesofconduct).

If they are to carry any weight, they will need to be backed up by certification, and research institutions will need to extend their often flimsy means of assuring compliance. Less demandingly, good behaviour can be encouraged by education, as illustrated at the meeting by Nobel laureate Phillip Sharp with examples of courses on science ethics and best practice at the Massachusetts Institute of Technology.

Codes of practice have so far attracted little attention in the biology community. But in a world threatened by terrorism, governments are taking more interest in such codes, and scientists would do well to engage in a constructive discussion about what role they might play.

\title{
Playing the name game
}

Stem-cell biologists should not try to change the definition of the word 'embryo'.

ast month's meeting of the International Society for Stem Cell Research in San Francisco witnessed a bizarre semantic debate. - Delegates discussed a proposal to refrain from using the term 'embryo' when referring to the blastocysts from which human embryonic stem cells are harvested. The scientists involved reject the accusation that they are creating and destroying human lives, and fear that the word 'embryo' is a lightning rod that attracts negative scrutiny.

It is true that embryo is an emotive term, but there is little scientific justification for redefining it. Whether taken from a fertility clinic or made through cloning, a blastocyst embryo has the potential to become a fully functional organism. And appearing to deny that fact will not fool die-hard opponents of this research. If anything, it will simply open up scientists to the accusation that they are trying to distance themselves from difficult moral issues by changing the terms of the debate.

At the equivalent meeting last year, the society decided to formally adopt the term 'somatic cell nuclear transfer' to describe the procedure in which an adult cell nucleus is transplanted into an egg to produce embryonic stem cells. This procedure had been called 'therapeutic cloning' to distinguish it from 'reproductive cloning', which would use the same technique in an attempt to make a baby.

But the work is far from yielding any therapies, and scientists realized that the word 'cloning' was generating public concern. So they decided to adopt a more technical term less likely to stir up strong emotions. At least that re-branding had the positive effect of toning down the hype surrounding therapeutic cloning.

The name change debated at last month's meeting would be a step too far, however. In the future, researchers may isolate pluripotent stem cells from biological entities that do not have the same developmental potential as embryos. This may justify the creation of a new set of words. Until then, stem-cell biologists should stick to debating the merits and ethics of their work using clear and simple language. They have a strong case to make that will not be helped by playing semantic games in an effort to evade scrutiny. 